\title{
COR TRIVENTRICULARE: INFUNDIBULAR STENOSIS WITH SUBDIVISION OF THE RIGHT VENTRICLE
}

\author{
BY \\ D. C. WATLER AND L. WYNTER \\ From the Departments of Pathology and Padiatrics of the Kingston Public Hospital, Jamaica, West Indies
}

Received February 20, 1961

While some 37 cases of cor triatriatum have now been reported (Niwayama, 1960) only two cases of triventricular hearts have been recorded, both recently, and we think it of some interest to report two further cases of this anomaly seen by us in a three-year period (1957-1959).

\section{CASE REPORTS}

Case 1. A boy, aged 6 years, was admitted to hospital for the first time with early congestive cardiac failure, severe orthopnœa, cyanosis and gross clubbing of the fingers and toes. The heart was enlarged clinically and a systolic murmur was heard over the entire præcordium. Radiography of the chest showed a grossly enlarged heart with reduced pulmonary vascularity (Fig. 1). Hb. was 14.0 g. per $100 \mathrm{ml}$., R.B.C. $6,000,000$ per cu. mm., and E.S.R. (Westergren) $1 \mathrm{~mm}$./hr. Despite treatment for the cardiac failure, the child's condition rapidly deteriorated and he died four days after admission.

Autopsy Findings. The heart was grossly enlarged, due mainly to right ventricular hypertrophy and dilatation, but also to slight left ventricular hypertrophy. The venous return to the right atrium was normal and the foramen ovale was anatomically patent but physiologically closed by the normal valve. The right atrium was dilated and communicated normally with the right ventricle through the tricuspid orifice which was widely patent. The wall of the right ventricle

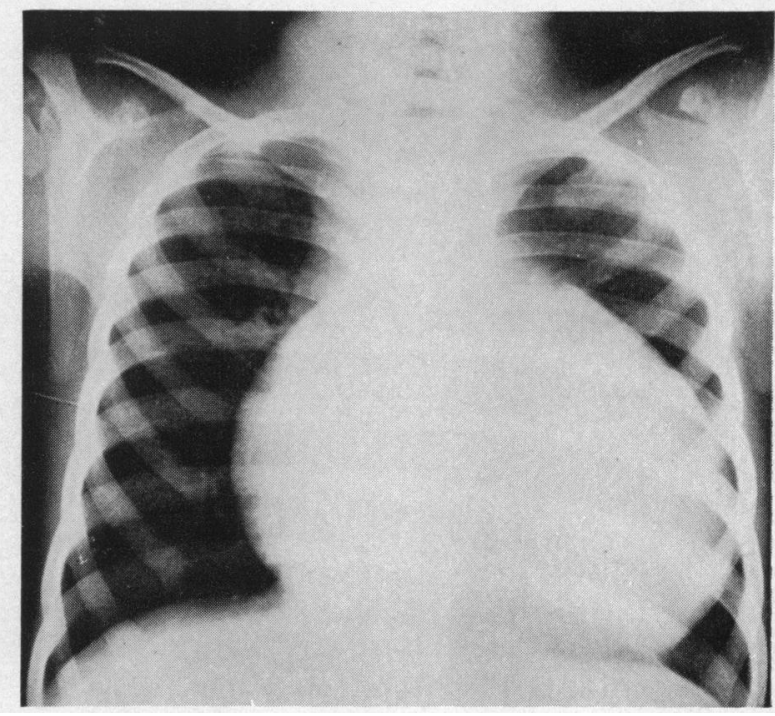

Fig. 1.-Case 1. Gross cardiac enlargement and reduced pulmonary vascularity. was $10 \mathrm{~mm}$. thick, and it communicated by means of a narrow opening (4 mm. long, $3 \mathrm{~mm}$. wide) with a small accessory or infundibular ventricle situated in an antero-superior position to the main right ventricle. This accessory chamber (or infundibular ventricle) was $40 \mathrm{~mm}$. long, its wall $10 \mathrm{~mm}$. thick, and the pulmonary trunk arose from it (Fig. 2). The pulmonary valve was bicuspid and a mild degree of valvular stenosis was present with slight post-stenotic dilatation. The left atrium was considerably smaller than the right atrium and received blood by the pulmonary veins in the usual way. It communicated normally with the left ventricle which was moderately hypertrophied (wall $8 \mathrm{~mm}$. thick). A high interventricular septal defect was present, the foramen being $8 \mathrm{~mm}$. by $6 \mathrm{~mm}$. 
The aorta arose directly above this defect, and overrode both proper ventricular cavities. The aortic valve had three cusps and the ductus arteriosus was closed. While the post-mortem appearances of the other viscera indicated congestive cardiac failure, the lungs were pale and avascular.

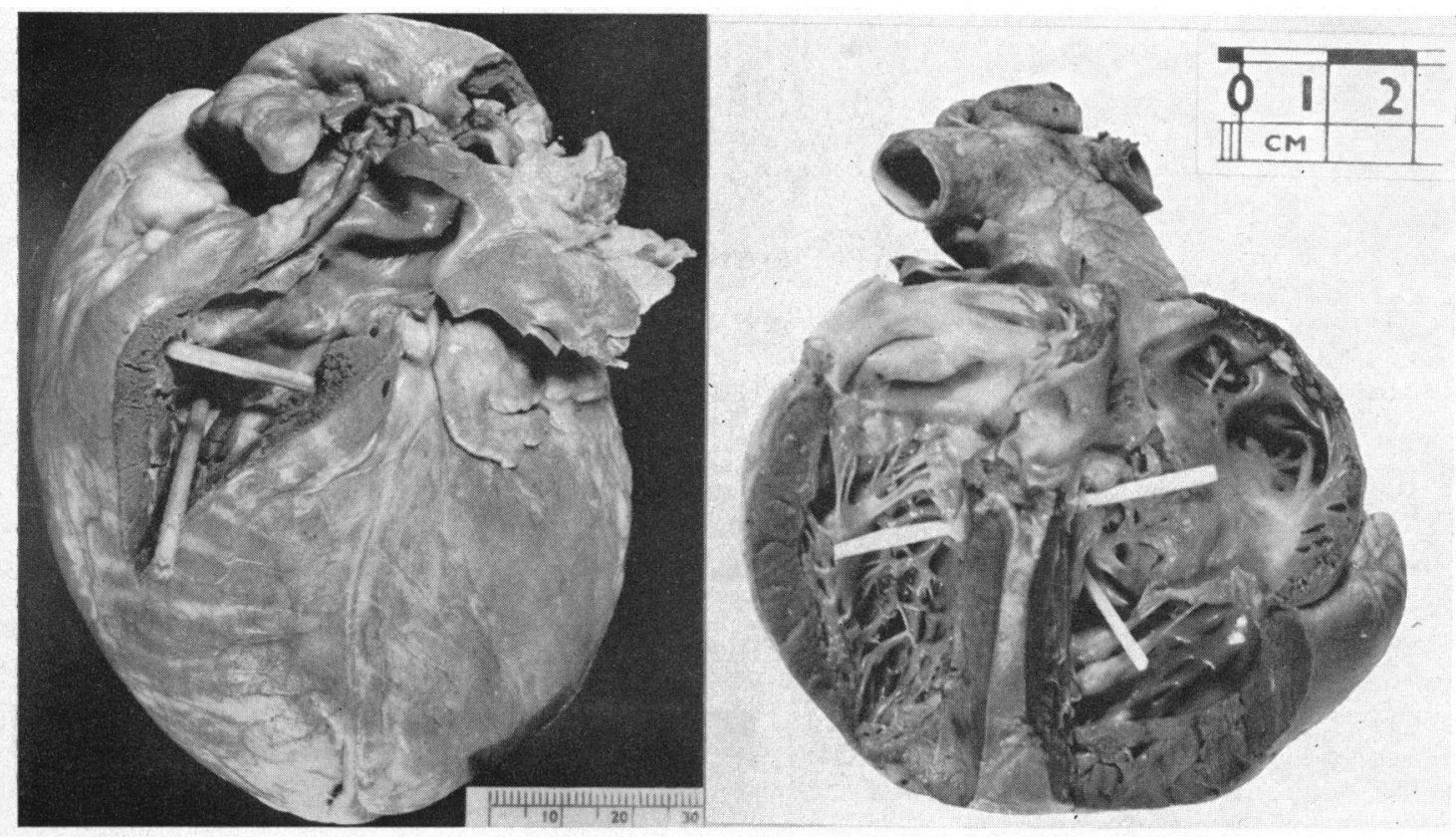

FIG. 2.-Case 1. Infundibular ventricle with the pulmonary trunk rising from it. The probe is in the ostium infundibuli.
FIG. 3.-Case 2. The upper probe passes through the ventricular septal defect. The lower probe is in the ostium infundibuli.

Case 2. A girl, aged 3 years 10 months, had been dyspnœic since birth and had been attending hospital from the age of one. From the first examination gross cyanosis and clubbing of the fingers and toes were noted. A systolic murmur was usually audible over the præcordium but on occasions was entirely absent. Radiography of the chest showed slight cardiac enlargement with clear lung fields. $\mathrm{Hb}$. was $16.3 \mathrm{~g}$. per $100 \mathrm{ml}$., W.B.C. 10,500 per cu. mm., and E.S.R. (Westergren) $1 \mathrm{~mm}$./hr. The child went into cardiac failure and died rapidly despite all resuscitative measures.

Autopsy Findings. Apart from minor differences, the autopsy findings were the same as those described for Case 1. In this case the foramen ovale was entirely closed; the right ventricle was hypertrophied (wall $9 \mathrm{~mm}$. thick) and communicated through a small opening $(3 \mathrm{~mm}$. long by $2 \mathrm{~mm}$. wide) with a small anterosuperior, accessory chamber $(30 \mathrm{~mm}$. long, and $5 \mathrm{~mm}$. thick). From this chamber the pulmonary trunk arose, and the pulmonary valve was again bicuspid. No pulmonary valve stenosis was present. The left atrium communicated normally with the left ventricle and there was a high interventricular septal defect $(10 \mathrm{~mm}$. by $8 \mathrm{~mm}$.). The aorta was overriding the defect but appeared to take origin mainly from the right ventricle proper (Fig. 3 and 4). As in case 1 the aortic valve was normal and the ductus arteriosus closed. There was some evidence of early congestive cardiac failure, but this was not as marked as in the previous case.

\section{Discussion}

A search for earlier reports of cases with defects similar to those observed by us revealed only two (Brodie, 1945; Hakkila and Hakkila, 1954). In Brodie's case which died at the age of one year, there was an accessory ventricle communicating with the right ventricle through a narrow opening 


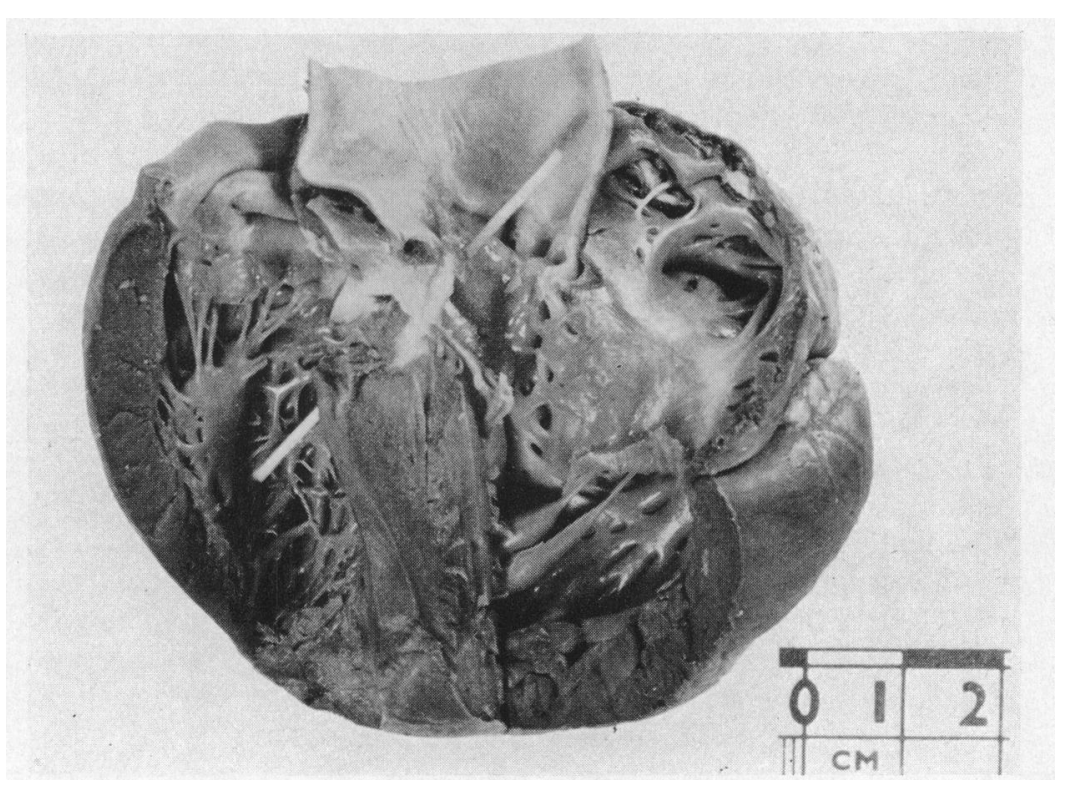

FIG. 4.-Case 2. The overriding aorta rises mainly from the right ventricle. The probe passes through the ventricular septal defect.

( $5 \mathrm{~mm}$. in diameter), and the aorta arose from the right ventricle. No pulmonary stenosis was present. This case was designated cor biatrium triloculare, but this appears wrong to us as such a name implies a common ventricle with two atria. The term cor triventriculare was apparently first used by Hakkila and Hakkila (1954) and this name obviously describes the anatomy of the defect accurately. Their patient died at the age of 32; three ventricles were present, but the opening from the accessory ventricle to the right ventricle was large $(15 \mathrm{~mm}$. by $10 \mathrm{~mm}$.), and an infundibular pulmonary stenosis was present with complete dextroposition of the aorta and a ventricular septal defect. In our cases, and in the other two cited, the pulmonary valve was bicuspid. The basic abnormality in all of them is obviously the same, the particularly remarkable feature being the presence of an accessory or infundibular ventricle. In all the patients there was some degree of dextroposition of the aorta with a high ventricular septal defect.

In considering the circulation of the blood through the heart in our two cases, it is easy to understand the reasons for the profound cyanosis and dyspnœa. Blood entering the right ventricle could only reach the lungs through the narrow opening into the accessory ventricle with resultant massive right ventricular hypertrophy. Some escape of venous blood into the systemic circulation must have occurred through the overriding aorta by virtue of the high pressure developed in the main right ventricle. Oxygenated blood returning to the left heart may also have become mixed with venous blood in the right ventricle through the ventricular septal defect, and a further mixing might have occurred in Case 1 in which the foramen ovale was still not anatomically closed. In Case 2 in which the aorta arose almost completely from the right ventricle, more venous blood must have entered the systemic circulation than in Case 1 in which the aorta overrode both ventricles. It should be noted, however, that it is not always easy to determine accurately at autopsy the degree of aortic override, and the only accurate method of deciding this appears to be selective angiocardiography during life (Keith, Rowe, and Vlad, 1958).

The basic defect in cor triventriculare would seem to be a disturbance in the absorption and fate of the bulbus cordis in its formation of the right ventricle. Normally at the fifth to sixth intrauterine week the bulbus cordis divides into the infundibulum and aortic vestibule, the former being separated 
from the right ventricle proper by ridges of mesenchymal tissue. As the pulmonary and aortic valves are being formed, absorption of excess mesenchymal tissue occurs, so that by the seventh week the constriction between the lower end of the infundibulum and right ventricle has begun to disappear and finally it remains only as the infundibulo-ventricular crest (crista supraventricularis). In cor triventriculare it is suggested that there is a failure in the absorption of the mesenchymal tissue leading to a permanent and abnormal partition between the right ventricle and infundibulum, the latter becoming in fact an accessory ventricle, and only communicating with the right ventricle proper by means of a narrow opening in the infundibulo-ventricular crest (ostium infundibuli).

The principal defect in cor triventriculare can therefore be considered to be a severe form of infundibular stenosis, and as such these cases are in fact a rare type of Fallot's tetralogy. As in Fallot's tetralogy the other anomalies that are present, dextroposition of the aorta and a high ventricular septal defect, can be explained by abnormalities of the septation and absorption of the bulbus cordis.

Keith (1909) studied in detail the various types of infundibular stenosis, and stressed the importance of malabsorption of the bulbus cordis in the genesis of the different anomalies. He described three cases of subdivision of the right ventricle similar to those seen by us. He commented further that where the size of the ostium infundibuli is only $2-4 \mathrm{~mm}$. in diameter, the patient dies early in life, while if the opening is wide (6-15 $\mathrm{mm}$.), the patient often survives to adult life. While not many cases of this type of infundibular stenosis have been described, it is possible that the condition is not as rare as may be supposed.

\section{SUMMARY}

Two unusual cases of triventricular hearts are described in which the right ventricle is partitioned into two chambers, the smaller of which is placed antero-superiorly and gives off the pulmonary trunk. Other anomalies present are high interventricular septal defect, overriding aorta and bicuspid pulmonary valves. Only a few cases of this anomaly appear to have been described. The possible pathogenesis is discussed and its relationship to Fallot's tetralogy is considered.

We are grateful to Professor Harper, of the University College of the West Indies for helpful suggestions and criticisms relating to the embryology of the two cases; also to Dr. Maurice Lev, of the Congenital Heart Disease Research and Training Center in Chicago, for reviewing photographs of these patients, and helpful suggestions as to their correct designation.

\section{REFERENCES}

Brodie, J. (1945). J. Path. Bact., 57, 481.

Hakkila, R., and Hakkila, J. (1954). Ann. med. int. fenn., 43, 170.

Keith, A. (1909). Lancet, 2, 359.

Keith, J. D., Rowe, R. D., and Vlad, P. (1958). Heart Disease in Infancy and Childhood. p. 399. The Macmillan Company, New York.

Niwayama, G. (1960). Amer. Heart J., 59, 291. 